\title{
Performance of a solar PV tracking system on tropic regions
}

\author{
Y. Garcia, O. Diaz \& C. Agudelo \\ Faculty of Engineering, University of Cundinamarca, Colombia
}

\begin{abstract}
Climate change is currently a large concern for human society, particularly our high dependence on fossil fuels. A considerable amount of research effort is focused on renewable energies, especially solar photovoltaic (PV) generation systems. For solar PV systems, energy conversion efficiency is an active research topic, with many approaches being developed to solve this problem. One of these approaches is solar tracking systems, where the solar PV moves with the sun in order to capture the maximum direct solar radiation. This paper proposes a solar PV single-axis tracking system and compares the energy conversion efficiency with respect to a fixed solar PV installation. The proposed mechanical system is based on a servomotor moving a PV on a shaft, covering 180 degrees. A sevenelement sensor is used to measure and estimate the angle of maximum solar radiation. Also, a control system was used to obtain the optimal power output from the solar PV. The system was tested in Fusagasugá, Colombia, which is located in the tropics region.

Keywords: solar PV, renewable energy, solar tracker, single-axis tracker, tropic region.
\end{abstract}

\section{Introduction}

Photovoltaic (PV) systems are used to convert sunlight into electricity. They are safe, reliable and can replace energy from non-renewable sources that pollute the environment. Ideally the photovoltaic modules are designed to provide the largest amount of power at minimal cost; however, in order to have the highest power output, the PV array needs to capture the maximum possible amount of radiation, thus the PV array needs to be pointing as close as possible towards the sun. The performance of PV systems is affected by the orientation and tilt angle because 
these parameters determine the amount of solar radiation received by the surface of a PV module in a particular region.

Solar trackers are automated solar panels that actually follow the sun to increase the power output from the panel. Solar trackers can be used for several applications such as solar cells, solar day-lighting system and solar thermal arrays [1, 2]. The solar tracking systems are very useful and attractive due to their increased efficiency compared to a fixed panel with no tracking movement.

Regarding solar tracking systems, there are two main classifications according to rotation axes: single rotation axis or dual rotation axis.

- Single-rotation axis uses only one degree of freedom, moving the panel in one direction. Those systems use a simple mechanical configuration with only one motor drive. Energy loss due to mechanical friction is minimal due to its simplicity. Also, a simple one-dimensional control mechanism is used to drive the tracking system; however, sun tracking is limited and cannot do the tracking accurately in regions with seasonal changes. Those systems are commonly used under tropical weather conditions, where the sun movement can be simplified to one dimension.

- Dual-rotation axes use two degrees of freedom in order to track the sun more closely along the current day and current season. Power conversion efficiency is better when compared with the previous single-axis system; however, those systems need a complex mechanical configuration with two motor drives, and they require a complex two-dimensional control system. Compared with the single-axis configuration the dual-axes systems are more expensive. This dual-axes configuration is better suited to seasonal regions, where the sun movements are more complex.

A view about single-axis and dual-axis configurations is shown in Figure 1.
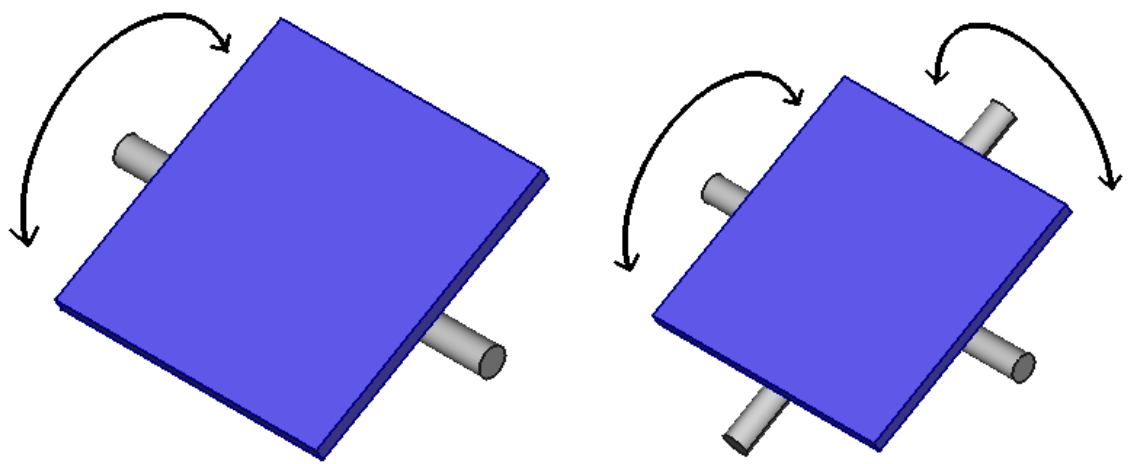

Figure 1: Single-axis and dual-axes configurations.

This paper presents a single-axis configuration prototype, tested in the town of Fusagasugá, located at the following coordinates: latitude $4^{\circ} 20^{\prime} 14^{\prime \prime}$ north and longitude $74^{\circ} 21^{\prime} 52^{\prime \prime}$ west. This region has a tropical dry climate type and thus it 
has favorable weather conditions for solar energy. The average radiation measured in the region is $4.82 \mathrm{kWh} / \mathrm{m}^{2}$ per day [3,4], providing reasonable amount of power from solar radiation.

\section{Previous work}

There are several works related to PV solar tracking around the world. One interesting paper from Alexandru [2] proposed a design and a simulation of a single-axis tracker for PV modules. In this study a virtual prototype of the tracking system is performed, which integrates the mechanical device and the control system, in a mechatronics concept.

Deepthi et al. [5] proposed the comparison of the single-axis solar tracking and dual-axes solar tracking with a fixed mount solar system. In this work, dual-axes tracking systems had better performance than single-axis solar tracking systems during cloudy days, but were more expensive.

Other authors such as Mejia et al. [6] presented an optimization algorithm for solar tracking which improved the panel efficiency by up to $35 \%$ [7]. In this study the efficiency of three silicon solar modules were measured: poly-crystalline, mono-crystalline and amorphous silicon, by applying a single-axis solar tracking system under the tropical wet climate of Malaysia.

Huang et al. [8] proposed a solar PV system with improved efficiency by using a single-axis three-position sun tracking system. This system measured up to a $37 \%$ increase in total power generation compared to the fixed PV system.

On the other hand, Stamatescu et al. [9] presented a solar tracking algorithm for control of the photovoltaic panel movement; this algorithm was implemented and an experimental platform using a tri-positional control strategy was built.

Tudorache et al. [10] presented a solar tracking PV system using a DC motor controlled by an intelligent drive unit that receives input signals from dedicated light intensity sensors. The recorded data proved that the solar tracking panel produced around $57.55 \%$ more energy than the fixed system.

\section{Prototype description}

The proposed prototype consists of two parts. The first part is a mechanical system with a metallic shaft that supports the PV panel, bound to a servomotor and a structure made of balsa lumber and wood. This structure is $56 \mathrm{~cm} \mathrm{long,} 24 \mathrm{~cm}$ wide and $26 \mathrm{~cm}$ high. The PV panel has an area of $572 \mathrm{~cm}^{2}$ and it can move at angles from $-80^{\circ}$ to $+80^{\circ}$ with respect to the vertical axis.

$\mathrm{V}-\mathrm{I}$ and the power measurement circuit together with a Data Acquisition (DAQ) board are attached to the base structure. The DAQ provided measurement data to a PC with a LabView application to store it in a database and exported it to a spreadsheet for further analysis. A brief block diagram of the prototype is shown in Figure 2. 


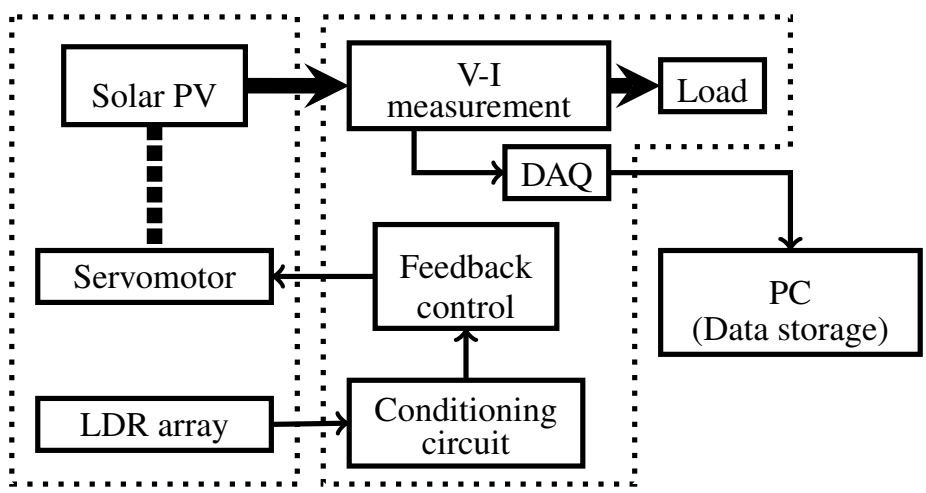

Figure 2: Block diagram of the tracker prototype.

The base wood structure, together with the shaft, the mounted solar PV and the servomotor is shown in Figures 3 and 4. Also, a detailed sequence of the prototype construction process is shown in Figure 5.

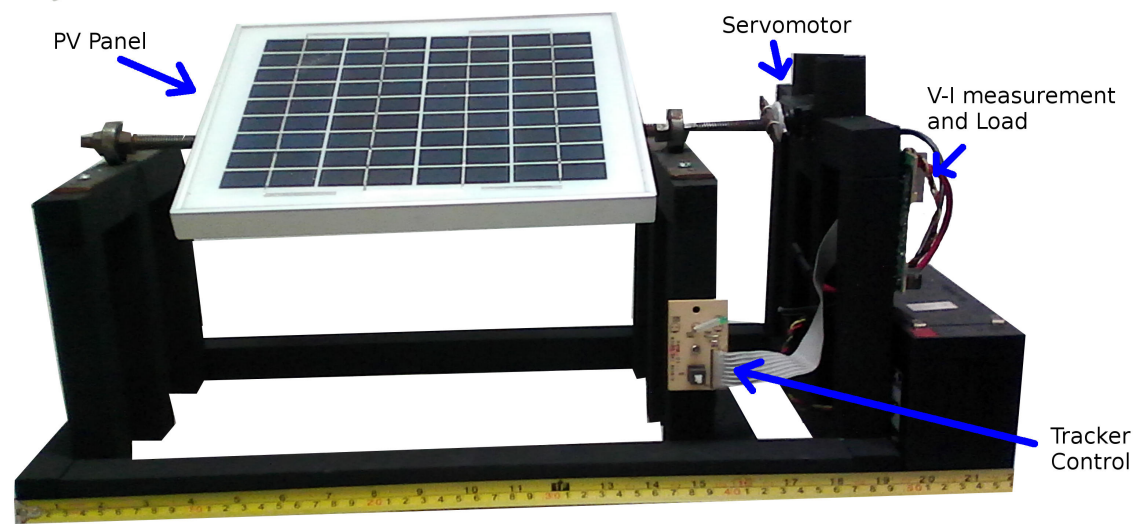

Figure 3: Details of the tracker system - front view.

The solar PV used for the experiment is fabricated by INTI, its technical characteristics are summarized in Table 1. Two identical panels were used for the experimental setup: one of them was installed in the single-axis tracker system, and the other was set up in a configurable fixed-angle structure, also made of balsa lumber.

The second part of the solar PV tracker is the light dependent resistor (LDR) array sensor. This sensor consists of an array of seven LDRs in an arc structure made of balsa lumber, as shown in Figure 6 . This structure is $40 \mathrm{~cm}$ long, $20 \mathrm{~cm}$ wide and $27 \mathrm{~cm}$ high. Each of the LDR elements detects a peak at certain angles 


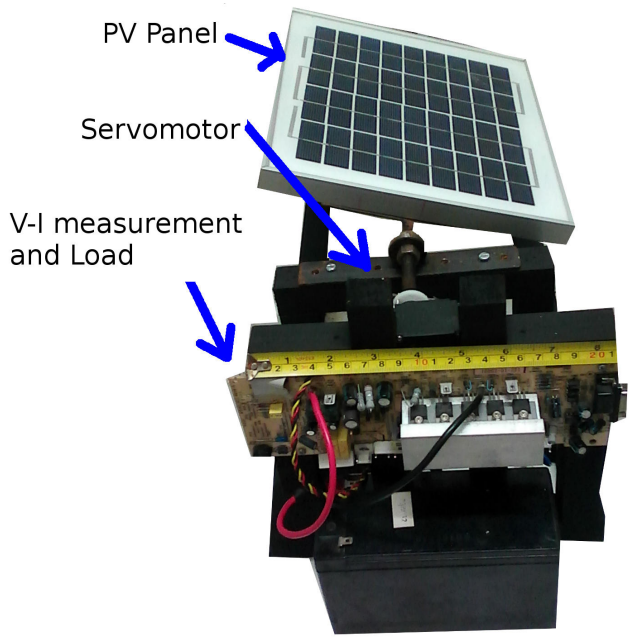

Figure 4: Details of the tracker system - side view.

Table 1: PV characteristics.

\begin{tabular}{|c|c|}
\hline Manufacturer & INTI \\
\hline Model & IPS 5 \\
\hline Cell type & Poly-cristaline \\
\hline Maximum power & $5 \mathrm{~W} \pm 3 \%$ \\
\hline Voltage on maximum power & $18.36 \mathrm{~V}$ \\
\hline Maximum current & $0.27 \mathrm{~A}$ \\
\hline Open circuit voltage & $22 \mathrm{~V}$ \\
\hline Short circuit current & $0.29 \mathrm{~A}$ \\
\hline Cell efficiency & $15.72 \%$ \\
\hline Dimensions & $260 \mathrm{~mm} \times 220 \mathrm{~mm} \times 18 \mathrm{~mm}$ \\
\hline Operating temperature & From $-40^{\circ} \mathrm{C}$ to $85^{\circ} \mathrm{C}$ \\
\hline
\end{tabular}



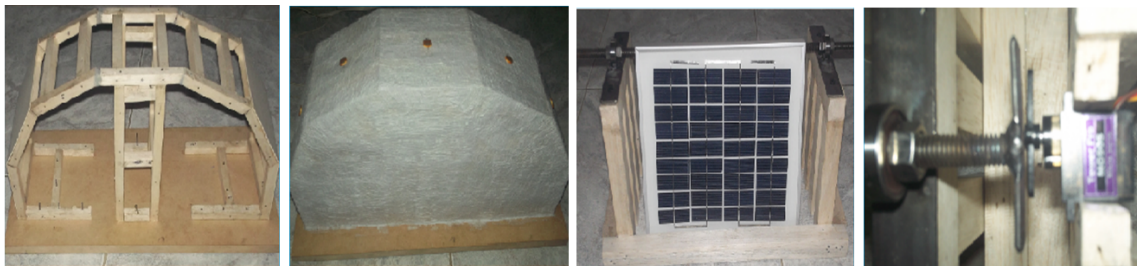

Figure 5: Details of the construction process.

and the neighbors of the LDR fine tune the measured angle. A conditioner circuit converts the array signals into a tracking angle. This configuration allows the angular position of the sun to be detected with a high accuracy. Prior to taking the measurements, the LDR array was calibrated to return the angle of maximum radiation. Other array configurations with two or five sensors have been used in previous studies [11], but these used simpler sensors which were less accurate.

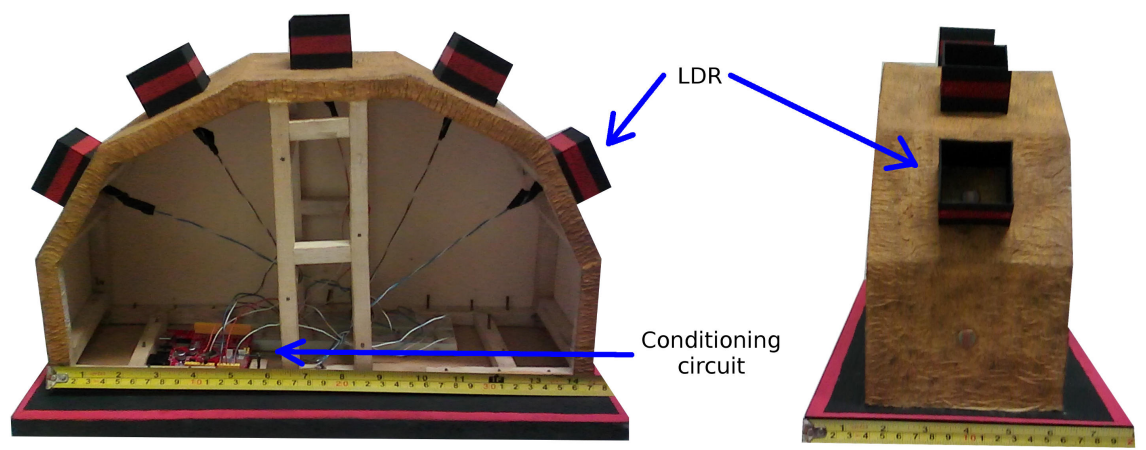

Figure 6: Detail of the LDR array sensor.

A simple feedback control system was used to drive the servomotor and this control system was configured to set the normal vector of the solar PV panel at the same angle as the maximum sun brightness.

\section{Methodology}

In order to compare the performance of single-axis tracking with a fixed mounted configuration, two identical PV panels were used and installed in the following ways: one panel was mounted with a fixed tilt angle of 15 degrees towards the east; and the second panel was mounted to the tracking system. Both PV panels were aligned conveniently, going over the east-west direction. Both panels used in the tracking and fixed systems have the same model and manufacturer, thus assuming same characteristics. 
The DAQ device was programmed to take measurements at ten minute intervals, with the current and voltage samples taken from both PV panels. The measured voltage is the open circuit voltage $V_{O C}$, which is measured when the solar cell has no load or $R_{L} \rightarrow \infty$. The measured current is the short circuit current $I_{S C}$, which is measured when the solar cell has a low resistance load or $R_{L} \rightarrow 0$. Both $V_{O C}$ and $I_{S C}$ can be used to calculate the theoretical power of the cell $P_{T}$, by calculating $P_{T}=V_{O C} \times I_{S C}$.

Measurements were taken from 08:00 to 18:00. Also, since the biggest difference in terms of power occur after 12:00, a special time range from 12:00 to 17:00 is considered for detailed analysis.

The proposed system was tested under similar weather conditions: sunny days with few clouds. This was the predominant weather during the period in which the experiments took place.

\section{Results}

The first results are shown in Figure 7; this is the comparison of the measured power $P_{T}$ for both the fixed and tracker configuration. In addition, a summarized comparison table is shown in Table 2.

Table 2: Comparison of average values.

\begin{tabular}{|l|c|c|}
\hline Variable & Fixed panel & Tracking panel \\
\hline $\bar{V}_{O C}$ & $19.8 \mathrm{~V}$ & $20.4 \mathrm{~V}$ \\
\hline $\bar{I}_{S C}$ & $225.1 \mathrm{~mA}$ & $272.1 \mathrm{~mA}$ \\
\hline $\bar{P}_{T}$ & $4.5 \mathrm{~W}$ & $5.6 \mathrm{~W}$ \\
\hline Power gain & - & $24.5 \%$ \\
\hline
\end{tabular}

The power comparison figure also shows that there is no significant difference between the configurations during the morning period (before 12:00); however, after noon the power comparison presents larger differences. This can be explained by the tilt angle of the fixed panel; the fixed panel had a tilt angle that favored power output in the morning (closer to the east) and disfavored power in the afternoon.

A $V_{O C}$ voltage comparison is shown in Figure 8. This shows that both configurations presented a relatively constant voltage (around $20 \mathrm{~V}$ ) during daylight conditions. This can be explained with the PV physics and photoelectric effect; that voltage output depends on the photon energy or frequency. 


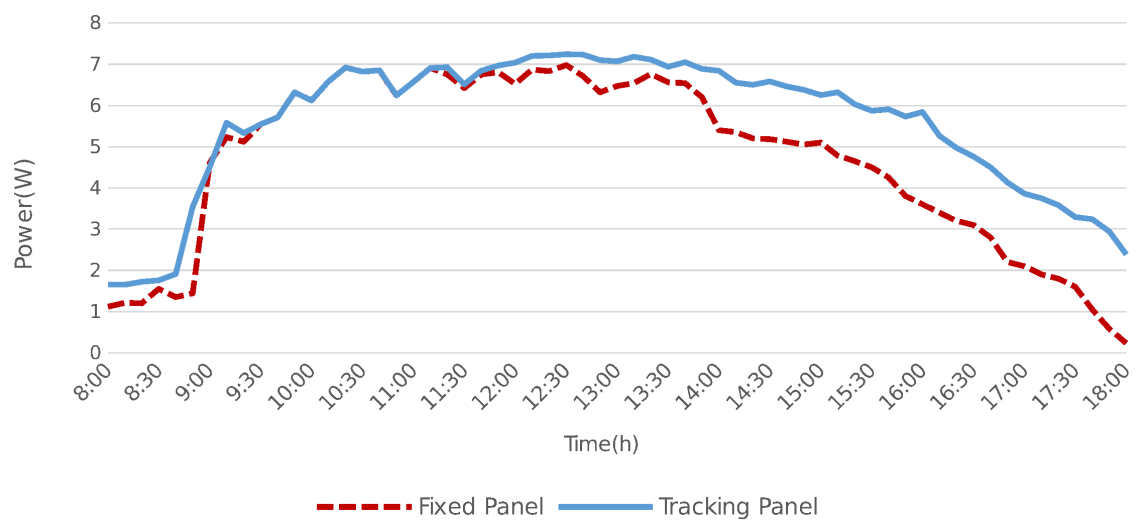

Figure 7: Power comparison $\left(P_{T}\right)$.

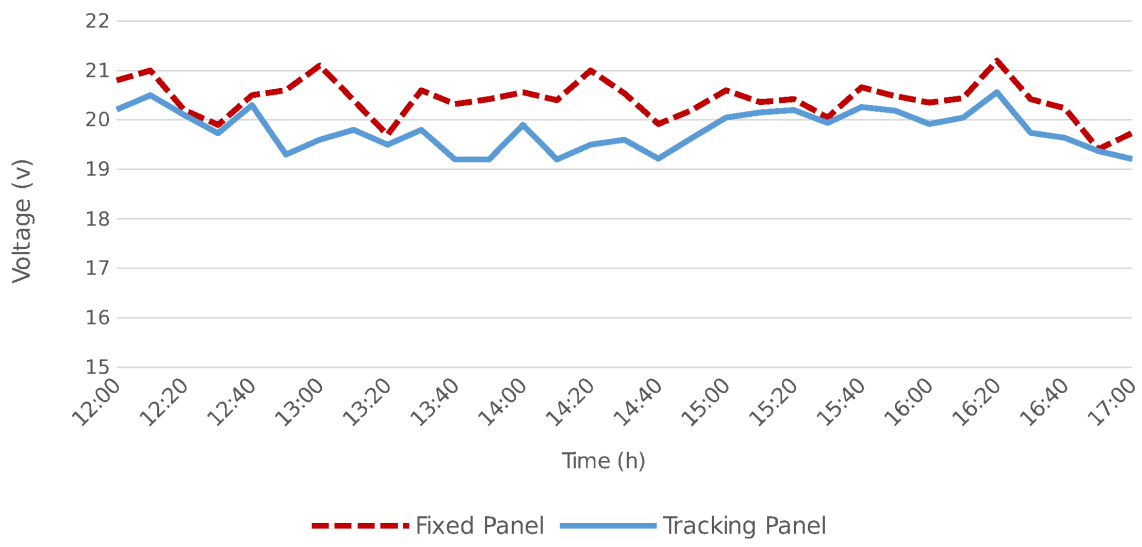

Figure 8: Voltage comparison $\left(V_{O C}\right)$.

A $I_{S C}$ current comparison is shown in Figure 9. Since the $V_{O C}$ can be considered constant, the current curve is quite similar to the $P_{T}$ comparison figure.

\section{Conclusions}

This paper presents the design of a single-axis tracker solar PV prototype and its experimental results were presented. These results showed an important improvement in power conversion: around $25 \%$ more power with respect to a fixed panel configuration.

The experimental setup measured the I-V characteristics during the tests, and the power was calculated from these results. The voltage in the solar PV is approximately constant in daylight conditions, this is consistent with the physics of PV. Therefore, the current measurement is sufficient to get the power conversion 


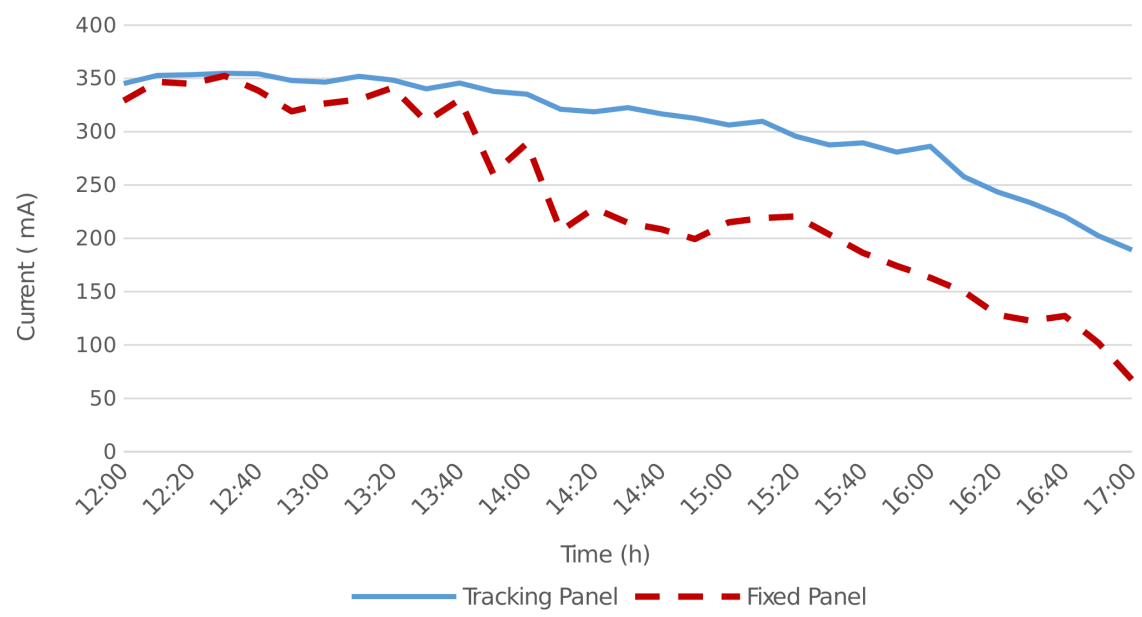

Figure 9: Current comparison $\left(I_{S C}\right)$.

efficiency. Precision improvements in the current sensor can be done to get more accurate data.

This single-axis tracker configuration can be used on larger scale PV panels, for tropic regions like Fusagasugá and, in general, most of the towns and regions in Colombia.

Future work will include using different technologies in solar PV, for example using mono-crystalline and amorphous silicon PV panels. Also, the checking of the use of a maximum power point tracker system instead of the maximum radiation point used in this paper and comparing these two tracking methods. Since the use of a single-axis tracker on tropic regions has given good results so far, there is no plan to compare it with a dual-axes tracker in the foreseeable future.

\section{References}

[1] Ahmad, S., Shafie, S. and Kadir, M.Z.A.A., Power feasibility of a low power consumption solar tracker. Procedia Environmental Sciences, 17, pp. 494-502, 2013. The 3rd International Conference on Sustainable Future for Human Security, 2012, 3-5 November 2012, Clock Tower Centennial Hall, Kyoto University, Japan.

[2] Alexandru, C., Design and optimization of a monoaxial tracking system for photovoltaic modules. Journal of Solar Energy, p. 6, 2013. doi: $10.1155 / 2013 / 586302$.

[3] Nasa surface meteorology and solar energy. Available from: https://eosweb.larc.nasa.gov/sse/.

[4] Swera solar and wind energy resource assessment. Available from: http://maps.nrel.gov/swera/. 
[5] Deepthi, S., Ponni, A., Ranjitha, R. and Dhanabal, R., Comparison of efficiencies of single-axis tracking system and dual-axis tracking system with fixed mount. International Journal of Engineering Science and Innovative Technology, 2, pp. 425-430, 2013.

[6] Mejia, A.E., Londoño, M.H. and Osorio, J.C., Diseño e implementación de un seguidor solar para la optimización de un sistema fotovoltaico. Scientia et Technica, 1(44), pp. 245-250, 2010.

[7] Ghazali M, A. and Abdul Rahman, A.M., The performance of three different solar panels for solar electricity applying solar tracking device under the Malaysian climate condition. Energy and Environment Research, 2(1), p. 235, 2012.

[8] Huang, B.J., Huang, Y.C., Chen, G.Y., Hsu, P.C. and Li, K., Improving solar PV system efficiency using one-axis 3-position sun tracking. Energy Procedia, 33, pp. 280-287, 2013. PV Asia Pacific Conference 2012.

[9] Stamatescu, L., Făgărăşan, L., Stamatescu, G., Arghira, N. and Iliescu, S.S., Design and implementation of a solar-tracking algorithm. Procedia Engineering, 69, pp. 500-507, 2014. 24th DAAAM International Symposium on Intelligent Manufacturing and Automation, 2013.

[10] Tudorache, T., Oancea, C.D. and Kreindler, L., Performance evaluation of a solar tracking PV panel. University Politehnica of Bucharest Scientific Bulletin, Series C: Electrical Engineering, 74(1), pp. 3-10, 2012.

[11] Tudorache, T. and Kreindler, L., Design of a solar tracker system for PV power plants. Acta Polytechnica Hungarica, 7(1), pp. 23-39, 2010.

[12] Molina, J.P., Jiménez, R.D., Gama, E.N., Ramos, O.L. and Duque, J., Diseño e implementación de un prototipo de vehículo solar con almacenamiento de energía. Revista Científica, 18, pp. 159-165, 2014.

[13] Buß, D., Strobel, M. and Koentopp, M., Influence of technological changes on the energy yield of PV modules: An outdoor study. Energy Procedia, 55, pp. 38-46, 2014. Proceedings of the 4th International Conference on Crystalline Silicon Photovoltaics.

[14] Espitia, H. and Sierra, F., Diseño e implementación de controladores análogos para un seguidor solar. Visión Electrónica: algo más que un estado sólido, 7(1), pp. 118-132, 2013.

[15] Koussa, M., Haddadi, M., Saheb, D., Malek, A. and Hadji, S., Sun tracker systems effects on flat plate photovoltaic PV systems performance for different sky states: A case of an arid and hot climate. Energy Procedia, 18, pp. 839-850, 2012. Terragreen 2012: Clean Energy Solutions for Sustainable Environment.

[16] Mousazadeh, H., Keyhani, A., Javadi, A., Mobli, H., Abrinia, K. and Sharifi, A., A review of principle and sun-tracking methods for maximizing solar systems output. Renewable and Sustainable Energy Reviews, 13(8), pp. 1800-1818, 2009.

[17] Muñoz, Y., Guerrero, J. and Ospino, A., Evaluation of a hybrid system of renewable electricity generation for a remote area of colombia using homer software. TECCIENCIA, 9(17), pp. 57-67, 2014. 
[18] Oko, C., Diemuodeke, E., Omunakwe, E. and Nnamdi, E., Design and economic analysis of a photovoltaic system: A case study. International Journal of Renewable Energy Development, 1(3), 2012.

[19] Soulayman, S. and Sabbagh, W., Optimum tilt angle at tropical region. International Journal of Renewable Energy Development, 4(1), 2015.

[20] Ye, J.Y., Ding, K., Reindl, T. and Aberle, A.G., Outdoor PV module performance under fluctuating irradiance conditions in tropical climates. Energy Procedia, 33, pp. 238-247, 2013.

[21] Aja, O.C., Amin, N., Alghoul, M.A. and Al-Kayiem, H.H., Design of an intelligent dual-axis solar tracking device for solar system usage. Proceedings of the 3rd (2011) CUTSE International Conference, Miri, Sarawak, Malaysia, 2011. 